\title{
FATORES CRÍTICOS PARA ALINHAMENTO NACIONAL DA LEGISLAÇÃO DE SEGURANÇA CONTRA INCÊNDIO E PÂNICO
}

\section{RESUMO}

\author{
Ednei da Silva Factum dos Anjos ${ }^{1}$ \\ Ricardo Bernardes Frank ${ }^{2}$ \\ Ivan Ricardo Fernandes ${ }^{3}$
}

Trata-se de um estudo sobre os principais desafios para o alinhamento da legislação de segurança contra incêndio e pânico, abrindo discussão sobre o tema da codificação em plano nacional. O problema identificado foi 0 questionamento quanto aos fatores críticos a esse alinhamento e, de forma subjacente, das possíveis implicações advindas de uma norma geral de aplicação nacional. Como hipótese, emerge que o processo de retificação desse normativo depende de mobilização política, legislativa e técnica dos Corpos de Bombeiros Militares do país. É, pois, relevante e atual e se justifica pela imperiosa necessidade de instrumentalização e padronização de norma nacional unificadora de procedimentos administrativos e de exigência de medidas mínimas de segurança. Teve como objetivo geral identificar e contextualizar os fatores críticos ao alinhamento; e, especificamente, objetivouse mapear a atual situação da legislação correlata em plano nacional. $O$ método utilizado, de caráter qualitativo, foi a pesquisa bibliográfica exploratória, e análise comparativa entre a legislação vigente e as instruções normativas aplicáveis à espécie em três Estados da Federação. Como balizadores teóricos têm-se RAMOS (2007); BERTO (2015); SILVA (2002); bem como as NBRs da ABNT, e as NRs MTE. Da análise dos dados obtidos, percebeu-se que a edição de norma nacional unificadora da legislação contribuirá para maior difusão de cultura de segurança ou de prevenção, devido à significativa ampliação do conhecimento da norma e à maior facilidade de adequação dos projetos e das construções. Espera-se, pois, inaugurar discussão ampla e uniforme sobre o tema e divulgação da necessidade de conhecimento e cumprimento de suas normas técnicas, o que tem potencial de possibilitar contribuição social e acadêmica.

Palavras-chave: Fatores Críticos. Alinhamento. Unificação de Legislação. Segurança contra Incêndio e Pânico. Corpo de Bombeiros Militar.

\footnotetext{
${ }^{1}$ Bacharel em Direito (UFBA) e Comandante do 5ํGBM. edneifactum@gmail.com

${ }^{2}$ Bacharel em Direito (UCSAL) e Comandante do 13ํGB. rb.frank@yahoo.com.br

${ }^{3}$ Mestre e doutorando em Engenharia Civil (PUC-PR) e Tenente Coronel do Corpo de Bombeiros da Polícia Militar do Paraná. ivan@pm.pr.gov.br
} 


\title{
CRITICAL FACTORS FOR NATIONAL ALIGNMENT OF FIRE AND PANIC SAFETY LEGISLATION
}

\begin{abstract}
This is a study on the main challenges for the alignment of fire and panic safety legislation, opening discussion on the subject of codification at national level. The problem identified was the questioning of the critical factors to this alignment and, subjacently, of the possible implications arising from a general norm of national application. As a hypothesis, it emerges that the process of rectification of this normative rule depends on political, legislative and technical mobilization of the Military Fire Brigades of the country. It is, therefore, relevant and current, and it is justified by the imperious need of instrumentalization and standardization of a national norm that unifies administrative procedures and demands for minimum safety measures. The general objective was to identify and contextualize the factors critical to alignment; and, specifically, the objective was to map the current situation of the correlated legislation at a national level. The method used, of a qualitative nature, was exploratory bibliographic research, and comparative analysis between the current legislation and the normative instructions applicable to the species in three states of the Federation. RAMOS (2007); BERTO (2015); SILVA (2002); as well as the ABNT's NBRs and the MTE's NRs. From the analysis of the data obtained, it was realized that the edition of a national standard unifying the legislation will contribute to greater dissemination of safety culture or prevention, due to the significant expansion of knowledge of the standard and the greater ease of adequacy of projects and buildings. It is expected, therefore, to initiate a broad and uniform discussion on the subject and dissemination of the need for knowledge and compliance with its technical standards, which has the potential to enable social and academic contribution.
\end{abstract}

Keywords: Critical Factors. Alignment. Unification of Legislation. Fire and Panic Safety. Military Fire Department. 


\section{INTRODUÇÃO}

O presente trabalho tem por pretensão apresentar os principais desafios para alinhamento da legislação de segurança contra incêndio e pânico ao nível nacional. Os chamados códigos de incêndio possuem eficácia estadual, posto que são constituídos por leis, decretos, portarias e instruções normativas estaduais.

Deste modo, cada Estado da Federação possui um arcabouço normativo próprio, de eficácia limitada ao território do respectivo ente federativo. Não fossem as inúmeras cidades de fronteira, indústrias e empresas de construção civil com atuação nacional e, até, transnacional, as diferenças legislativas teriam pouca importância prática. Vale dizer, cada empreendedor tem de estabelecer processos construtivos diferentes para cada Estado, sob pena de ter seu projeto rejeitado ou, na pior hipótese, sua edificação em desconformidade com a legislação local e, portanto, impossibilitada de habitação e de funcionamento.

Nesse sentido, inúmeros entraves podem ser percebidos, os quais, por óbvio, impactarão no desenvolvimento econômico e social da região. É certo que peculiaridades locais podem impor normas específicas de controle e funcionamento a cargo de Estados e Municípios: clima, relevo e, até, aspectos culturais podem, sim, figurar como fatores determinantes de restrição ou de liberalidade para certas exigências construtivas.

Ocorre, no entanto, que tais características locais não podem servir de impedimento ao estabelecimento de uma coluna vertebral normativa de âmbito nacional que unifique os procedimentos administrativos e fixe os preventivos mínimos de segurança contra incêndio e pânico; como, por exemplo: os ritos administrativos para realização de análise de projeto, de vistoria, aplicação de multa, defesa administrativa e, principalmente, o estabelecimento de um cabedal mínimo contendo medidas passivas e ativas de segurança. 
No que tange aos procedimentos a serem seguidos pelo interessado, os ditos procedimentos administrativos, o que impressiona é a diversidade de roteiros postos aleatoriamente, por cada Corporação Bombeiro-Militar, à disposição do usuário, muita vez, confundindo-o e, até, impedindo a consecução de seus objetivos de regularização da edificação ou área de risco pelos órgãos competentes, e o consequente prejuízo à prevenção e à proteção contra incêndio e pânico. Muitos ficam pelo caminho burocrático e desistem de regularizar sua obra ou edificação e, como não é possível fiscalizar tudo, a segurança vê-se prejudicada por entraves meramente administrativos.

Desta maneira, reveste-se de especial esforço analógico a edição de uma norma que estabeleça, não apenas as exigências mínimas de segurança, mas também formas e procedimentos dos diversos atos administrativos reclamados entre o requerimento inicial e a aprovação do projeto ou a expedição do chamado Auto de Vistoria do Corpo de Bombeiros (AVCB), sem, por óbvio, prescindir das garantias processuais da ampla defesa e do contraditório, mormente no que tange à aplicação das sanções administrativas e ao indeferimento de pedidos.

A ausência de norma jurídica nacionalmente unificadora da segurança contra incêndio e pânico contribui para o desconhecimento do processo administrativo de regularização de projetos e de edificações e, por conseguinte, para o descumprimento das exigências mínimas de segurança, especialmente, por empresas e corporações transnacionais. Logo, o foco do problema da pesquisa é a investigação dos fatores críticos ao alinhamento da legislação federal de segurança contra incêndio e pânico, e, de forma subjacente, das possíveis implicações advindas de uma norma geral de aplicação nacional.

As grandes seguradoras internacionais vinculam o valor do prêmio ao atendimento de normas técnicas de segurança de amplitude global. Nesse sentido, empresas que atuam em vários países podem estabelecer o mesmo contrato de seguro para suas filiais e sede espalhadas pelo planeta, sem 
necessidade de modificar seu parque industrial a cada nova localidade sede, valendo-se de normas técnicas de aplicação supranacional, tais como as normas advindas da National Fire Protection Association (NFPA). A NFPA é uma organização americana que tem o objetivo de estabelecer normas $e$ padrões para segurança contra incêndio.

Um código de incêndio unificado nacionalmente tem potencial para reduzir recursos de tempo e de material, especialmente pelo aproveitamento das fases de elaboração de projetos e de insumos da etapa construtiva. A iniciativa privada poderá formatar seus projetos a uma realidade única em todo território nacional, sem descontinuidade de seus processos internos. Os ganhos, quer pela economia de tempo, quer pela maximização de recursos, podem promover melhores resultados econômicos e financeiros.

Muito se discute acerca da impropriedade de se estabelecer normas gerais de segurança contra incêndio e pânico, vez que as peculiaridades continuariam a ser díspares e, portanto, reguladas por normas específicas. Ocorre que, como se verá adiante, defende-se que a competência legislativa de tal matéria é privativa da União, nos termos do inciso XXVIII, do art. 22, somente cabendo aos Estados legislar quando autorizados por lei complementar federal: "lei complementar poderá autorizar os Estados a legislar sobre questões específicas das matérias relacionadas neste artigo" (BRASIL, 1988). Não se trata, por oportuno, como querem alguns, de competência concorrente, consubstanciada nos $\S \S 3^{\circ}$ e $4^{\circ}$, do art. 24 . Isto porque segurança contra incêndio e pânico melhor se enquadra ao conceito de defesa civil, presente no inciso XXVIII, do art. 22, do que a quaisquer das matérias constantes do art. 24 (BRASIL, 1988). Bom que se pontue, por oportuno, que o Supremo Tribunal Federal (STF) tem nítida inclinação em validar a legislação estadual vigente, mediante interpretação que, por razões históricas, informa tratar-se de competência concorrente, embora não se perceba adequação da segurança contra incêndio e pânico ao direito urbanístico ou à proteção e à defesa da saúde, conforme se demonstrará adiante. O que compatibiliza 
desejo dos Estados federados de preservação de suas atribuições nessa seara.

\section{FUNDAMENTAÇÃO TEÓRICA}

Em linhas gerais, todas as edificações e áreas de risco, de aglomeração de público, bem como as destinadas à realização de eventos programados, sejam públicas, sejam privadas, por ocasião de construção ou fabricação, reforma ou ampliação de área construída, mudança de ocupação ou uso, aumento de altura, necessitam de aprovação no Corpo de Bombeiros Militar do Estado de situação do imóvel, afora as de uso residencial, exclusivamente unifamiliares e algumas outras poucas exceções (BAHIA, 2013).

Esta admissão ou reprovação, pelo Corpo de Bombeiros Militar, condiciona-se, não apenas ao cumprimento das normas relativas à segurança contra incêndio e pânico propriamente ditas, mas também às regras que informam o devido trâmite e instrução da documentação comprobatória exigida no percurso da protocolização dos requerimentos de análise do projeto construtivo ao de vistoria do imóvel. Assim, no modelo atual, um mesmo projeto ou edificação pode ser aprovado em um Estado e rejeitado em outro, causando impactos no tempo de liberação para início das obras e, consequentemente, para o seu término. O que, via de regra, trará reflexos financeiros e sociais.

As medidas de segurança atuam especialmente na prevenção de incêndios e pânico, além de colaborar de forma decisiva no combate e extinção eficientes das chamas e no resgate de possíveis vítimas. Por isto, as análises de projetos e as vistorias técnicas constituem, senão o principal braço de uma instituição bombeiro-militar, o primeiro atendimento ao seu público externo no que se refere à antecipação de medidas acautelatórias de eventos potencialmente danosos à vida, ao patrimônio e ao meio ambiente.

Para fim de delimitação da competência legislativa, importante compreender em que se inserem as normas de segurança contra incêndio e pânico. Tem-se que a defesa civil está enquadrada no conceito de desastres e, embora estes, dentro da realidade brasileira, caracterizem-se pela frequência 
de eventos danosos naturais e cíclicos, especialmente as inundações em todo o país e a seca na região nordeste, aí não se esgotam. Vale dizer, há uma grande diversidade de desastres, quer naturais, quer humanos, quer mistos ${ }^{4} .0$ crescente aumento dos desastres humanos tem por prováveis causas 0 crescimento urbano caótico, as migrações internas e o fenômeno da urbanização acelerada, desordenada e sem a disponibilidade suficiente dos serviços essenciais. A Secretaria Nacional de Proteção e Defesa Civil (SEDEC), acerca de sua missão institucional, afirma em sítio oficial na internet que:

Sua atuação tem o objetivo de reduzir os riscos de desastres. Também compreende ações de prevenção, mitigação, preparação, resposta e recuperação, e se dá de forma multissetorial e nos três níveis de governo federal, estadual e municipal - com ampla participação da comunidade (BRASIL, 2020 - grifos nossos).

O Código de Incêndio e Pânico impõe a instalação de sistemas preventivos e protetivos, de forma a prevenir ou mitigar desastres. Cada catástrofe impõe a movimentação das engrenagens que compõem o sistema de proteção e defesa civil que, pela aprendizagem nos sucessivos eventos, sem olvidar de suas etapas, constroem-se mecanismos de antecipação de medidas visando a evitar ou minimizar os efeitos de futuros desastres.

Feita a correlação entre defesa civil e segurança contra incêndio e pânico, tem-se que a Constituição da República de 1988 outorga competência privativa à União para, dentre outras matérias, legislar sobre defesa civil ${ }^{5}$, assegurando aos Estados, por lei complementar autorizadora, competência para legislar sobre questões que Ihes sejam específicas ${ }^{6}$. Então, apesar da íntima relação entre defesa civil e segurança contra incêndio e pânico, a União, até o presente

\footnotetext{
${ }^{4}$ Vide classificação adotada pelo Sistema Nacional de Proteção e Defesa Civil e aprovada pelo Conselho Nacional Proteção de Defesa Civil, a Codificação de Desastres, Ameaças e Riscos (CODAR).

${ }^{5}$ O inciso XXVIII, do art. 22, da Constituição da República de 1988, informa que "compete privativamente à União legislar sobre: defesa territorial, defesa aeroespacial, defesa marítima, defesa civil e mobilização nacional" (BRASIL, 1988).

${ }^{6}$ O Parágrafo único, do art. 22, da Constituição da República de 1988, assevera que "lei complementar poderá autorizar os Estados a legislar sobre questões específicas das matérias relacionadas neste artigo" (BRASIL, 1988).
} 
momento, não editou tal lei complementar autorizadora, de forma que a permissão constitucional para os Estados legislarem sobre defesa civil, embora tenha fundamento legal aderente ao Parágrafo único, do art. 22, da Lei Maior, encontra, como alternativa à ausência de expressa autorização, os $\S \S 3^{\circ}$ e $4^{\circ}$, do art. 24, da Carta Maior, como melhor se discutirá adiante.

Ainda na busca do fundamento da competência legislativa estadual para dispor sobre segurança contra incêndio e pânico, tem-se que a Constituição da República de 1988 confere à União, aos Estados e ao Distrito Federal competência concorrente para legislarem sobre direito urbanístico e proteção e defesa da saúde ${ }^{7}$. O direito urbanístico engloba todas as regras jurídicas que versam sobre planejamento urbanístico, do uso e ocupação do solo urbano (parcelamento, loteamento, proteção ambiental), da ordenação da atividade edilícia (zoneamento, licenças urbanísticas) e da utilização de instrumentos de intervenção urbanística (desapropriação, tombamento, servidão administrativa). Assim, apesar de manter relação com a segurança contra incêndio e pânico, o direito urbanístico centra sua atenção na política urbana, voltada principalmente ao planejamento e ao controle do uso, do parcelamento e da ocupação do solo urbano, de modo a promover o adequado ordenamento territorial, pouco se voltando às questões de defesa civil e, consequentemente, às de segurança contra incêndio e pânico, senão apenas indiretamente.

Em igual medida, não há que se falar em proteção e defesa da saúde, constante do inciso XII, do art. 24, da vigente Constituição da República, por óbvias razões. A tendência de validação ao desejo de preservação das atribuições dos Estados membros, quer por razões históricas, quer por questões políticas, não dá à segurança contra incêndio e pânico natureza de normas de proteção e defesa da saúde, vez que o escopo preventivo e mitigatório do código de incêndio vai muito além, salvaguardando o patrimônio, o meio ambiente e a vida, seja ela humana ou não.

\footnotetext{
${ }^{7}$ O inciso I e XII, do art. 24, da Constituição da República de 1988, declaram que "compete à União, aos Estados e ao Distrito Federal legislar concorrentemente sobre: direito tributário, financeiro, penitenciário, econômico e urbanístico" e "previdência social, proteção e defesa da saúde" (BRASIL, 1988).
} 
Registra-se, por oportuno, que esse entendimento não encontra ressonância em nenhum dos Estados da Federação, vez que todos aqueles que editaram os chamados códigos de incêndio e pânico o fizeram ao largo de norma federal autorizadora, buscando assento na competência concorrente. $O$ que, como veremos adiante, poderá constituir entrave ao alinhamento da legislação de segurança contra incêndio.

Aspecto importante a ser considerado no percurso à unificação nacional da legislação de segurança contra incêndio e pânico são as recentes leis federais sobre o tema, notadamente as advindas após o fatídico episódio do incêndio da Boate Kiss, na cidade de Santa Maria, Rio Grande do Sul, em 27 de fevereiro de 2013, tais como as Leis federais $n^{0} 13.425 / 2017$ e $n^{\circ}$ $13.722 / 2018$, as quais, além de aspectos gerias sobre o tema, trazem competências dos Corpos de Bombeiros Militares e dos municípios. Nesse diapasão, a Lei federal $n^{0} 13.675 / 2018$ e o Plano e Política Nacional de Segurança Pública e Defesa Social, com vigência para o período de 2018 a 2028, trazem indicação de elaboração de legislação na seara da segurança pública com forte tendência ao alinhamento. A novel legislação citada merece seção própria no presente esboço, adiante tratado.

As Normas Técnicas Brasileiras (NBRs), da Associação Brasileira de Normas Técnicas (ABNT), e as Normas Regulamentadoras de Segurança e Saúde do Trabalho (NRs), do Ministério do Trabalho e Emprego (MTE), são aplicáveis, em todo território nacional, às questões de proteção do consumidor, por força do inciso VIII, do art. 39, do Código de Defesa do Consumidor (CDC), Lei federal $\mathrm{n}^{0} 8.078$ de 11 de setembro de 1990, e às laborais, respectivamente:

art. 39. É vedado ao fornecedor de produtos ou serviços, dentre outras práticas abusivas:

VIII - colocar, no mercado de consumo, qualquer produto ou serviço em desacordo com as normas expedidas pelos órgãos oficiais competentes ou, se normas específicas não existirem, pela Associação Brasileira de Normas Técnicas ou outra entidade credenciada pelo Conselho Nacional de Metrologia, 
Normalização e Qualidade Industrial (CONMETRO). (BRASIL, 1990 - grifo nosso).

Destarte, desde 1990, tem-se experimentado norma geral aplicável em todo território nacional, cujas peculiaridades locais não demonstraram entrave à efetividade da presente norma legal. Segurança contra incêndio e pânico é alvo de inúmeras normas da ABNT e, na situação especial da Bahia, cujo código estadual de incêndio somente fora editado em 2013 e regulamentado apenas dois anos depois, sua aplicabilidade era recorrente, independentemente do mandamento do CDC, ante a ausência do legislador local.

As Normas Regulamentadoras de Segurança e Saúde do Trabalho (NRs), do Ministério do Trabalho e Emprego (MTE), a exemplo da NR $n^{0} 23-$ Proteção contra Incêndio, constante da Portaria SIT no 221, de 06 de maio de 2011, embora limitada em conteúdo, apresentam exigibilidade em âmbito nacional na esfera laboral. O item 23.1 informa que: "todos os empregadores devem adotar medidas de prevenção de incêndios, em conformidade com a legislação estadual e as normas técnicas aplicáveis" (BRASIL, 2011 - grifo nosso).

Bem assim, o legislador federal, nos anos de 2012, de 2017 e de 2018, editou normas jurídicas de aplicação em todo território nacional, disciplinando questões importantes de prevenção e proteção contra incêndio e pânico.

A Lei federal $n^{0} 12.608$, de 10 de abril de 2012, que institui a Política Nacional de Proteção e Defesa Civil - PNPDEC e dispõe sobre o Sistema Nacional de Proteção e Defesa Civil - SINPDEC e o Conselho Nacional de Proteção e Defesa Civil - CONPDEC, assim informa em seu art. 9:

art. 9ํㅡㄹ Compete à União, aos Estados e aos Municípios:

I - desenvolver cultura nacional de prevenção de desastres, destinada ao desenvolvimento da consciência nacional acerca dos riscos de desastre no País;

II - estimular comportamentos de prevenção capazes de evitar ou minimizar a ocorrência de desastres (BRASIL, 2012). 
Percebe-se forte tendência à universalização de procedimentos, ritos e protocolos de segurança que se apresentem capazes de favorecer a prevenção e a proteção da vida e do patrimônio diante do desastre. Nesse sentido, a Lei federal $n^{\circ} 13.425$, de 30 de março de 2017, estabelece diretrizes gerais sobre medidas de prevenção e combate a incêndio e a desastres em estabelecimentos, edificações e áreas de reunião de público, dentre outras providências.

Com vacância marcada para dois anos após sua publicação, a novel norma impôs aos prefeitos atribuição de atentar para necessidade de vistoria das edificações, antes de conceder alvará de funcionamento ou de habitação, sob pena de improbidade administrativa, com singular observância para as deliberações do Corpo de Bombeiros Militar, no que se refere às condições de segurança contra incêndio e pânico (art. 13, I).

\footnotetext{
Cabe ao Corpo de Bombeiros Militar planejar, analisar, avaliar, vistoriar, aprovar e fiscalizar as medidas de prevenção e combate a incêndio e a desastres em estabelecimentos, edificações e áreas de reunião de público, sem prejuízo das prerrogativas municipais no controle das edificações e do uso, do parcelamento e da ocupação do solo urbano e das atribuições dos profissionais responsáveis pelos respectivos projetos (BRASIL, 2017).
}

Inclui-se nas atividades de fiscalização do Corpo de Bombeiros Militar a aplicação de advertência, multa, interdição e embargo, na forma da legislação estadual pertinente. Os Municípios que não contarem com unidade militar instalada poderão criar e manter serviços de prevenção e combate a incêndio e atendimento a emergências, mediante convênio com a respectiva corporação militar estadual.

A Lei federal $n^{\circ} 13.675$, de 11 junho de 2018, que disciplina a organização e o funcionamento dos órgãos responsáveis pela segurança pública, nos termos do $\S 7^{\circ}$, do art. 144, da Constituição da República e cria a Política Nacional de Segurança Pública e Defesa Social (PNSPDS), precisamente em seu art. $5^{\circ}$, inciso XIII, prevê a "modernização do sistema e da legislação de acordo com a evolução social" (BRASIL, 2018a). Em igual sentido, as alíneas 
h, k e n, do Objetivo 15, do Plano e Política Nacional de Segurança Pública e Defesa Social (PPNSPDS), textualmente, expressam:

\begin{abstract}
Objetivo 15. Estabelecer política, programa de aparelhamento adequado e aprimorar procedimentos voltados a prevenção de situação de emergência e desastres:
\end{abstract}

h) Padronizar as ações de defesa civil nos órgãos de bombeiros civil e militares;

k) Incentivar a formação de um grupo de trabalho para uniformizar a legislação de segurança pública e elaboração de normas e procedimentos operacionais padrões (POP);

n) Promover a integração entre os três entes da Federação, para que se possam desenvolver projetos de redução de riscos de desastres, nos locais de maior vulnerabilidade dos Municípios (BRASIL, 2018d).

Por oportuno, percebe-se que a Política Nacional de Segurança Pública e Defesa Social e a lei federal que Ihe deu existência, acima mencionada, informam tendência à padronização de procedimentos em âmbito nacional. Há quem se incline pela impropriedade do estabelecimento de procedimento único para todo território nacional, visualizando graves divergências entre as diversas regiões do país. Sustentam que não é possível aplicar a mesma exigência normativa para todos os Estados da Federação, defendendo espécie de "grupo dos 13". Para estes, a desigualdade econômica e social entre as regiões do país constitui significativo entrave ao alinhamento legislativo.

A Portaria $\mathrm{n}^{0} 151$, de 26 de setembro de 2018, declara ser uma das atribuições da Secretaria Nacional de Segurança Pública "participar da elaboração de propostas de legislação em assuntos de segurança pública" (art. $1^{\circ}$, inciso XII, Regimento Interno), informando a primeira dimensão onde devem iniciar os trabalhos que visem ao alinhamento da farta legislação de segurança contra incêndio e pânico nos diversos Estados da Federação (BRASIL, 2018b).

A Secretaria Nacional de Segurança Pública, em 12 de julho de 2019, instituiu, mediante a Portaria $n^{\circ} 108$, Modelo Nacional de Regulamento de Segurança contra Incêndio e Emergências. A princípio, buscava-se oferecer 
parâmetro legislativo para incentivar a produção das normas de segurança contra incêndio e pânico nos Estados da Federação, ainda atrasados na edição do código de incêndio e pânico local. Por outro lado, analisando a contrario sensu essa iniciativa, vê-se clara convergência ao propósito de unificação legislativa, vez que a norma sugerida tinha por pretensão aplicação irrestrita a quaisquer dos Estados da Federação, demonstrando nítida aptidão para atuação em todo território nacional (BRASIL, 2019).

Os inúmeros precedentes legislativos analisados informam tendência à unificação. Em igual medida, o Departamento de Segurança e Prevenção contra Incêndio do CBM da PMESP, em resposta a quesito que indaga semelhanças entre a legislação paulista e de outros Estados da Federação, assim asseverou:

"O Corpo de Bombeiros da PMESP forneceu a legislação paulista para diversos entes federativos. Recentemente, após reunião entre integrantes dos Corpos de Bombeiros Militares do Brasil, foi identificado que 17 (dezessete) entes federativos utilizaram, de alguma maneira, a legislação de São Paulo na elaboração de suas normativas" (CBM PMESP, 2021).

Aproximadamente, 63\% dos Estados brasileiros já possuem certo alinhamento da legislação de segurança contra incêndio e pânico. O rigor científico e a forte experiência paulista, tanto nas ações operacionais de combate a incêndio quanto na produção de normas técnicas protetivas e preventivas $^{8}$, serviram de fonte de pesquisa e inspiração para corpos de bombeiros e legisladores estaduais de mais da metade do país.

\section{METODOLOGIA}

O método utilizado, sob viés qualitativo, foi a pesquisa bibliográfica com caráter exploratório em fontes e documentos oficiais, com anotações e análise comparativa entre a legislação vigente correlata e as instruções normativas

\footnotetext{
${ }^{8}$ As medidas de prevenção de incêndio são aquelas associadas ao subsistema de precaução contra o início do incêndio e se destinam, exclusivamente, a prevenir a ocorrência do início do incêndio, ou seja, controlar o risco de início do incêndio. As medidas de proteção contra incêndio, por sua vez, são aquelas destinadas a proteger a vida humana e os bens materiais dos efeitos nocivos do incêndio que já se desenvolve no edifício (BERTO, 2015, p. 3-4).
} 
(regulamentos e portarias) aplicáveis à espécie em três Estados da Federação, previamente definidos. Neste esboço, tomaram-se por parâmetro os Estados de Minas Gerais, Paraná e São Paulo devido à considerável tradição de seus Corpos de Bombeiros Militares, especialmente no que se refere à produção técnico-profissional, notadamente, à segurança contra incêndio e pânico.

A pesquisa, em um primeiro momento, realizou levantamento e seleção de documentos e normas, propondo à análise de conteúdos, mediante comparação entre as normas vigentes nos Estados de referência, de modo a analisar grau de conformidade entre os entes federativos da União, investigando possível tendência unificadora.

$O$ trabalho contou com a experiência vivida pelos autores nas cidades vizinhas de Juazeiro - BA e Petrolina - PE e de Teresina - PI e Timon - MA, quando perceberam in loco os entraves vividos por municípios vizinhos por legislações de eficácia regional no ano de 2014, durante Curso de Capacitação em Vistoria e Análise de Projetos, bem como continuidade de estudo do tema a partir de Especialização em Segurança contra Incêndio e Resgate, realizada em 2015, na Universidade Salvador (UNIFACS), mediante estudo acerca de unificação dos procedimentos administrativos de vistoria e de análise de projetos.

Demais disso, partindo da observação de padrão adotado pelos corpos de bombeiros militares, notadamente os recentemente emancipados, de aplicar as regras paulistas, demonstrou-se nítida tendência ao alinhamento legislativo, revelando que a reconhecida perícia do Corpo de Bombeiros Militar da Polícia Militar do Estado de São Paulo, na seara de segurança contra incêndio e pânico. Desta forma, os autores estabeleceram linha de pesquisa a partir de tal fator agregador, levando em conta forte tendência unificadora, ainda que informal, em torno das normas produzidas pelo CBM da PMESP.

A aplicação de questionário acerca do tema foco da pesquisa trouxe aos autores panorama explicativo da situação legislativa atual e das possíveis implicações de uma unificação institucional da legislação de segurança contra 
incêndio e pânico. Assim, a ferramenta Google Formulários foi o instrumento utilizado para aplicação de três questionários: o primeiro, a pesquisadores e professores especialistas, indicados pelos autores e pelo orientador, com atuação em diversos Estados; o segundo, a engenheiros e arquitetos que militam na área de segurança contra incêndio e pânico, preferencialmente, em mais de um Estado da Federação; e, por último, aos representantes máximos da área de atividades técnicas ou engenharia de segurança contra incêndio e pânico das Corporações Militares dos Estados da Bahia, de Minas Gerais, do Paraná e de São Paulo, com encaminhamento formal, mediante o Comando Geral do CBMBA.

A pesquisa atingiu 50 engenheiros, 5 arquitetos, 49 professores e 83 pesquisadores, totalizando 55 profissionais e 132 respostas válidas na área acadêmica, distribuídos em 19, dos 27 entes federados. Os três questionários foram aplicados no período de 26 de dezembro de 2020 a 23 de janeiro de 2021. A amplitude nacional da amostra coletada, atingiu $70,4 \%$ da Federação, com ampla participação do Estado da Bahia (74 entrevistados), Paraná (12 entrevistados) e Mato Grosso do Sul (13 entrevistados).

A análise desse estudo será feita de forma global, avaliando criticamente os resultados das pesquisas realizadas com professores e pesquisadores, engenheiros e arquitetos e com os Corpos de Bombeiros Militares dos Estados da Bahia, Minas Gerais, Paraná e São Paulo.

\section{ANÁLISES E RESULTADOS DA PESQUISA}

O alinhamento e, principalmente, a unificação da legislação de segurança contra incêndio e pânico encontram, como visto ao longo desse trabalho, alguns entraves políticos, legislativos e técnicos. Pode-se perceber que a definição do ente político estatal competente para legislar sobre a matéria é um dos primeiros e principais pontos críticos. $\mathrm{O}$ processo legislativo, com longas discussões e embates políticos locais e regionais envolvendo grupos de interesse, é, também, uma espécie de limitação. Outro fator determinante centra-se nas questões técnicas que, para muitos, requer definição pontual de temas regionais e locais. 
Figura 3 - Fatores críticos ao alinhamento

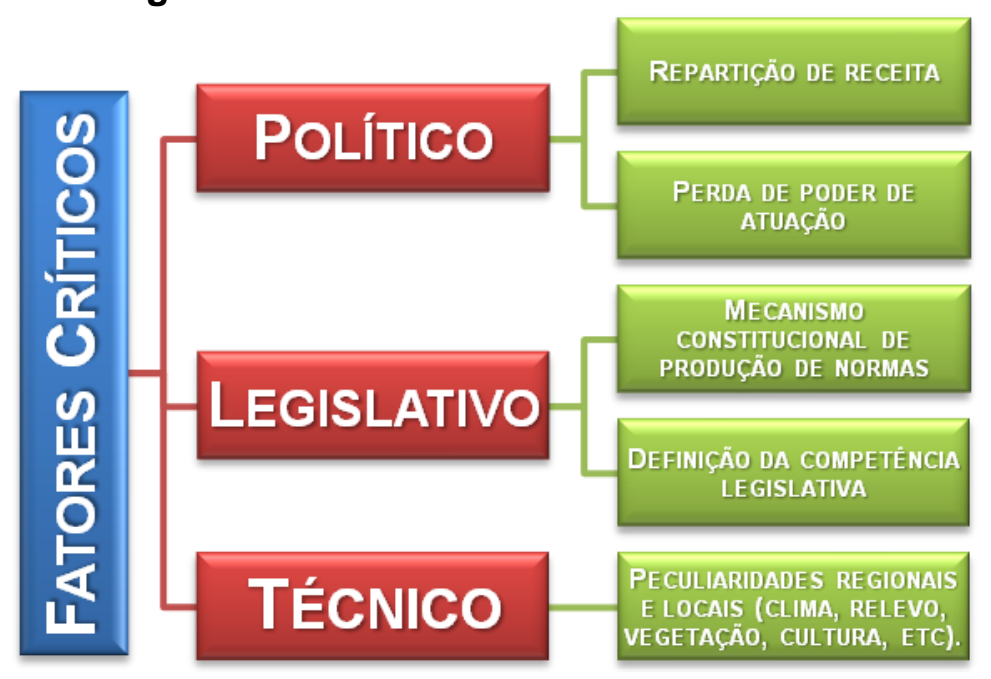

Fonte: Elaborado pelos autores (2021)

Na seara política, a definição do ente competente para legislar, por óbvio, implicará repartição de receita e, por consequência, divisão de poder de atuação. Uma lei federal unificadora deslocará do Estado para a União a competência legislativa e, assim, esta deverá definir a quem caberá fiscalizar e operar o sistema de aplicação de taxas e multas, estabelecendo destinação à receita, daí, proveniente.

Para alguns poucos, a quem se filiam os autores, a competência legislativa encontra-se delimitada no inciso XXVIII e Parágrafo único, do art. 22, da Constituição da República de 1988. Vale dizer, à União caberá a edição de normas gerais sobre defesa civil e, portanto, sobre segurança contra incêndio e pânico. Aos demais entes federativos, quando autorizados por lei complementar federal, competirá a produção de normas específicas destinadas à regulação de questões regionais.

Evidente que tal entendimento não implica falência dos Fundos de Arrecadação das taxas de incêndio e espécies congêneres. Isto porque a própria Carta Magna impõe que tal receita destina-se, exclusivamente, à 
preservação do serviço público efetivo e ou potencial que the deu causa. Vale dizer, taxa de incêndio é espécie tributária vinculada à prestação efetiva ou potencial dos serviços de prevenção e extinção de incêndios, destinando-se ao reaparelhamento da entidade fiscalizadora.

A taxa é, portanto, um tributo bilateral, contraprestacional e sinalagmático. Bilateral, porque encerra relação jurídica entre o contribuinte e o Fisco. Contraprestacional, posto que é vinculado a uma prestação estatal específica em favor do contribuinte e sinalagmático, por impor equilíbrio quantitativo entre o serviço público prestado e a obrigação imposta ao contribuinte. Tem-se, assim, que a taxa é cobrada pela prestação de serviços públicos, efetivos ou potenciais, ou pelo exercício do poder de polícia.

É exatamente essa característica contraprestacional que impõe a retroalimentação do sistema, justificando a preservação dos fundos de arrecadação em prol do respectivo Corpo de Bombeiros Militar.

A Constituição Federal de 1988, em seu art. 145, incorporou o conceito esboçado pelo Código Tributário Nacional (CTN), admitindo duas grandes espécies de taxas, sendo: Prestação de um serviço público $\rightarrow$ TAXA DE SERVIÇO ou UTILIZAÇÃO; e Prestação de um poder de polícia $\rightarrow$ TAXA DE POLÍCIA ou FISCALIZAÇÃO.

Figura 4 - Tipos de taxas no serviço público

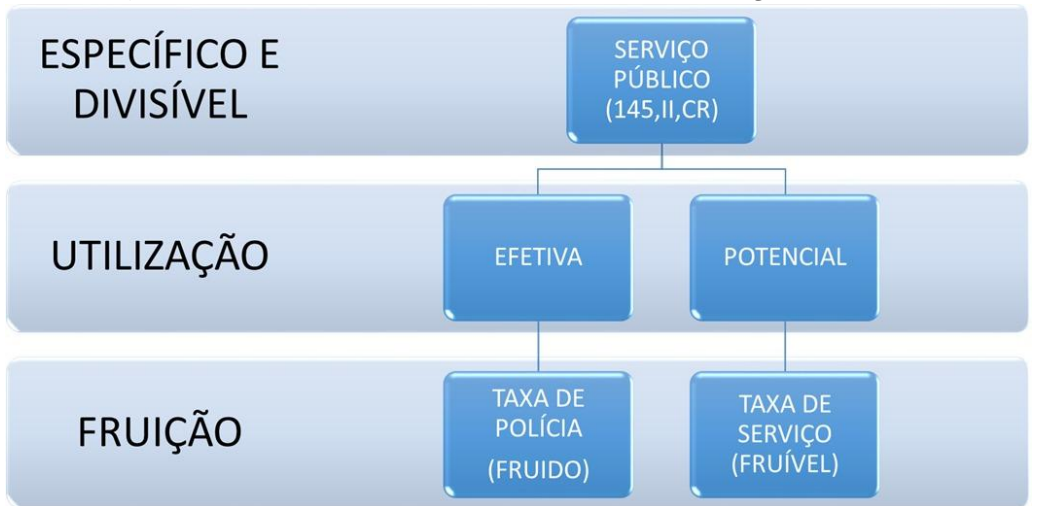

Fonte: Elaborado pelos autores (2020)

As taxas de serviço decorrem da utilização efetiva ou potencial de 
serviços públicos específicos e divisíveis, prestados ao contribuinte ou postos à sua disposição. Específico, singular ou uti singuli, refere-se àquele prestado em unidades autônomas de utilização e fruição; divisível, aquele passível de quantificação/individualização. São exemplos de serviço público específico e divisível, a energia elétrica, o fornecimento de gás, etc.. Os exemplos comportam bastante controvérsia na doutrina, pois o comum é que se cobre tarifa em tais casos, vez que não há restrição legal quanto à cobrança de preço público aos serviços essenciais. São também exemplos de taxa de serviço, a taxa de remoção de lixo, a taxa de coleta de esgoto e a taxa judiciária.

Quanto à utilização e fruição, a taxa poderá ser efetiva, quando ao contribuinte houver sido prestado materialmente o serviço público e, consequentemente, será classificado como fruído quando o particular tenha dele substancialmente usufruído. De outro lado, tem-se por potencial a taxa cujo serviço a ser prestado seja meramente posto à disposição do contribuinte, sem necessária fruição. É o que se dá, por exemplo, com os serviços de emergência e de extinção de incêndios. O Corpo de Bombeiros Militar põe-se de prontidão em seus quartéis, oferecendo ao particular a potencial garantia de um serviço no momento do acidente. A mera predisposição dos soldados do fogo enseja a cobrança da chamada taxa de incêndio pelo serviço potencialmente prestado e, portanto, meramente fruível, vez que a fruição somente se dará quando da ocorrência danosa.

Vencido o caráter vinculado da taxa, cabe analisar outra vertente interpretativa acerca da sede constitucional da competência para legislar sobre segurança contra incêndio e pânico. Diz posicionamento dominante, o qual informa a maioria dos códigos estaduais de incêndio e pânico, que tal competência decorre do inciso I ou XII e $\S \S 3^{\circ}$ e $4^{\circ}$, todos do art. 24 , da Constituição da República de 1988.

Preliminarmente, direito urbanístico refere-se às regras jurídicas que versam sobre planejamento urbanístico, uso e ocupação do solo urbano (parcelamento, loteamento, proteção ambiental), ordenação da atividade 
edilícia (zoneamento, licenças urbanísticas) e utilização de instrumentos de intervenção urbanística (desapropriação, tombamento, servidão administrativa). Embora tais matérias mantenham relação tangencial com a segurança contra incêndio e pânico, o direito urbanístico centra sua atenção na política urbana, voltada principalmente ao planejamento e ao controle do uso, do parcelamento e da ocupação do solo urbano, de modo a promover o adequado ordenamento territorial, pouco se voltando às questões de defesa civil e, consequentemente, às de segurança contra incêndio e pânico, senão apenas indiretamente.

Depois, proteção e defesa da saúde, presente no inciso XII, do art. 24, da Carta Maior parece limitar o escopo das normas de segurança contra incêndio e pânico, embora seja imperioso reconhecer tendência do STF de validação ao desejo de preservação das atribuições dos Estados membros, quer por razões históricas, quer por questões políticas. De qualquer forma, segurança contra incêndio e pânico volta-se à prevenção e mitigação dos efeitos de um incêndio, caminhando muito além da saúde, vez que visa a salvaguardar o patrimônio, o meio ambiente e a vida, seja ela humana ou não.

Outro fator limitante é o processo legislativo. O intricado mecanismo constitucional de produção de normas jurídicas configura significativo entrave à codificação, ao plano nacional, das normas de segurança contra incêndio e pânico. É o caso da confecção de anteprojeto de lei, discussão na câmara temática, audiências públicas, requerimento e aceitação deste pela mesa diretora da respectiva casa para inserção em pauta, discussão em duas casas legislativas, câmara e senado federais, votação dúplice, aprovação, sanção ou veto e publicação. Tudo isso, com ampla participação de representantes técnicos dos 26 (vinte e seis) Estados da Federação e do Distrito Federal.

$O$ terceiro fator limitante, aqui tratado, são as questões técnicas envolvidas para construção de um código nacional de incêndio e pânico. A vastidão do território brasileiro, a diversidade climática, de relevo, de vegetação e, até, cultural impõem atenção regionalizada para elaboração de norma eminentemente técnica. Ocorre que as questões políticas e legislativas, já 
tratadas acima, terminam por restringir a importância deliberativa do setor técnico, influenciando, não raro, de forma negativa, nesse processo.

Os três fatores limitantes tratados impuseram ao Estado da Bahia longa espera por um código estadual de incêndio e pânico. Somente em 2013, o código baiano fora publicado, aguardando mais dois anos para ser regulamentado, e, até a presente data, questões regionais importantes ainda esperam a edição de instruções técnicas. Se o percurso legislativo estadual fora marcado por tamanha expectativa, aguarda-se longa estrada na busca de um código nacional.

Tendo-se aberto o debate aos fatores críticos ao alinhamento da legislação de segurança contra incêndio e pânico, apresentam-se as análises e os resultados das pesquisas encaminhadas pelos autores.

Nesse sentido, importante a transcrição da resposta ao quesito que versa sobre a viabilidade da unificação da legislação de segurança contra incêndio e pânico. Diz o Departamento de Segurança e Prevenção contra Incêndio paulista:

"Em que pese o Brasil possuir dimensões continentais com especificidades regionais de cultura, clima e características construtivas, é interessante que a regra geral tenha o mesmo conteúdo. Não é interessante exigirmos medidas de segurança contra incêndio distintas apenas por ter ultrapassado a fronteira de um ente federativo" (CBM da PMESP, 2021).

Quanto ao resultado da pesquisa, propriamente dito, os itens seguintes apresentarão respostas aos questionários aplicados a professores e pesquisadores (área acadêmica), a engenheiros e arquitetos (área profissional) e aos Corpos de Bombeiros Militares dos Estados da Bahia, Paraná, Minas Gerais e São Paulo.

Quanto ao quesito acerca da competência para legislar sobre segurança contra incêndio e pânico, 51,5\% dos entrevistados responderam tratar-se de competência da União, 47\% Estados e Distrito Federal e 1,5\% Municípios. Professores e pesquisadores, praticamente, dividem-se na opinião acerca da sede da competência legislativa para elaboração de normas gerais sobre 
segurança contra incêndio e pânico, apresentando leve tendência favorável à União. A ausência de interesse político da União de legislar sobre segurança contra incêndio e pânico, traçando normas gerais, deslocou para Estados e Distrito Federal a responsabilidade de tratar desse importante assunto.

Com relação aos fatores adversos ao alinhamento legislativo, professores e pesquisadores demonstraram leve inclinação no sentido da predominância dos interesses políticos e econômicos, com 40,9\%, para entrave ao alinhamento legislativo, seguido pela divergência legislativa entre os códigos estaduais de incêndio e pânico, com 35,6\%, e, por último, com 23,5\%, impossibilidade de compatibilidade técnica das diversas peculiaridades locais.

É certo que peculiaridades locais e a enorme divergência dos inúmeros códigos estaduais de incêndio e pânico representam forte limitação ao alinhamento legislativo. Ocorre, no entanto, que são os interesses políticos e econômicos os maiores entraves à codificação nacional. Temas como a possibilidade de perda de receita e de gestão de fiscalização dão conta de debates intermináveis, movendo muito lentamente a atenção política do legislador federal, embora, como se verá adiante, tal alinhamento já se tenha operado tacitamente.

Com relação à fonte de inspiração dos demais Estados federados para construção de seus respectivos códigos de incêndio, 112 (cento e doze) dos 132 (cento e trinta e dois) entrevistados, responderam que a legislação paulista de segurança contra incêndio e pânico serviu de base aos demais Estados da Federação. Nesse sentido, quanto à unificação tácita, professores e pesquisadores responderam $85 \%$ positivamente e $14 \%$ não concordam.

O Departamento de Segurança e Prevenção contra Incêndio, do Corpo de Bombeiros Militar (CBM), da Polícia Militar do Estado de São Paulo (PMESP), referiu que 17 (dezessete) dos Estados Membros utilizaram, de alguma maneira, a legislação paulista na elaboração de seu respectivo código de incêndio e pânico, registrando oficialmente elevado grau de alinhamento tácito da legislação de segurança contra incêndio e pânico no país. 
Nesse sentido, foram, também, entrevistados, engenheiros e arquitetos, cujos resultados são, a seguir, apresentados. O processo de unificação dos diversos códigos de segurança contra incêndio e pânico depende de mobilização política, legislativa e técnica.

Nesse quesito, 27,3\% dos entrevistados reconheceram a aptidão natural dos corpos de bombeiros militares para capitanear processo de discussão de alinhamento da legislação. Assim, sabe-se que, efetivamente, é o corpo de bombeiros militar o órgão constitucionalmente competente para construção doutrinária do tema, não apenas por sua reiterada atuação na extinção de incêndios, mas, principalmente, pelo conhecimento desenvolvido em seus setores responsáveis pela prevenção e pela mitigação de tais desastres, precisamente em suas atividades operacionais de defesa civil, engenharia de segurança contra incêndio e pânico e, em maior medida, combate a incêndios.

Quanto à contribuição da unificação legislativa, engenheiros e arquitetos, em $14,5 \%$, entenderam que o alinhamento da legislação facilitará a adequação dos projetos construtivos e das edificações existentes à norma unificada de segurança contra incêndio e pânico, inexistindo quem apontasse inutilidade prática à unificação. A esmagadora maioria, $74,5 \%$, entendeu positivos os três fatores de contribuição indicados na pesquisa. Vale ressaltar que a unificação representará, na visão dos profissionais entrevistados, fomento à cultura de prevenção, difusão do conhecimento da legislação unificada e melhor adequação das edificações existentes e dos projetos construtivos à norma codificada.

Em igual sentido, diante da divergência da legislação de segurança contra incêndio e pânico entre os entes federados, $100 \%$ dos engenheiros e arquitetos afirmaram enfrentar dificuldade na realização de projeto construtivo para outro Estado da Federação. Impossível aplicar a mesma planta e, consequentemente, o mesmo processo produtivo a diferentes legislações de segurança, contribuindo negativamente para a celeridade e economicidade das construções e processo de produção. 
$\mathrm{Na}$ visão dos profissionais, engenheiros e arquitetos, a unificação legislativa tem solar conveniência aos objetivos comuns das instituições e atores envolvidos na segurança contra incêndio e pânico. Diz um dos engenheiros e arquitetos consultados: "A unificação da lei deverá acontecer, pois o objetivo desta é comum para todos: salvar vidas" (ENGENHEIRO I ARQUITETO, 2021).

Foi encaminhado ofício circular aos Corpos de Bombeiros Militares dos Estados da Bahia, Minas Gerais, São Paulo e Paraná. Buscou-se trazer ao trabalho a visão institucional de Corporações com farta experiência na área objeto do presente estudo, com o claro objetivo de identificar influência unificadora das normas de segurança contra incêndio e pânico.

Inicialmente, questionou-se se a elaboração da legislação de segurança contra incêndio e pânico (lei estadual e decreto regulamentador) daquele Estado utilizou alguma legislação estadual como inspiração ou parâmetro técnico norteador.

Pelo Comando de Atividades Técnicas e Pesquisas do CBMBA, foi dito que: "Sim". Afirmando, textualmente, ter-se valido das normas produzidas pelo Corpo de Bombeiros Militar da Polícia Militar do Estado de São Paulo (CBMBA, 2021).

O Estado de Minas Gerais disse que:

"A Lei $n^{\circ}$ 14.130, de 19 de dezembro de 2001, não foi elaborada tendo como base ou inspiração legislação de outro Estado. Já o Decreto no 43.805, de 17 de maio de 2004, primeiro decreto regulamentador sobre prevenção contra incêndio e pânico, no Estado de Minas Gerais, teve bastante similaridade com o Decreto $n^{\circ}$ 46.076, de 31 de agosto de 2001, do Estado de São Paulo" (CBMMG, 2021).

A lei de incêndio e pânico, normalmente, traz previsão de situações gerais, enquanto que sua regulamentação carece de detalhamento técnico multidisciplinar, normalmente, trazido da Corporação paulista, como, também, confirmou-se na situação mineira. 
Normas internacionais, leis federais e, sobretudo, as NBRs são, também, fontes de inspiração na construção do código estadual de incêndio e pânico.

Alguns poucos Estados da Federação, a exemplo de São Paulo e do Paraná, não se valeram de normas estaduais para elaboração de seu respectivo código de incêndio e pânico. A legislação paranaense apontada refere-se ao exercício do poder de polícia nas fiscalizações e aplicações de medidas administrativas de segurança contra incêndio e pânico.

O Estado das Minas Gerais trouxe especial contribuição ao tratar de normas de referência nacional sobre o tema, as quais foram pontuadas em seção própria desse trabalho, sob o título Precedentes Legislativos.

"O Corpo de Bombeiros da PMESP forneceu a legislação paulista para diversos entes federativos. Recentemente, após reunião entre integrantes dos Corpos de Bombeiros Militares do Brasil, foi identificado que 17 (dezessete) entes federativos utilizaram, de alguma maneira, a legislação de São Paulo na elaboração de suas normativas" (CBM da PMESP, 2021).

O CBM paulista confirmou suspeita de que, efetivamente, serviu de inspiração

a diversos Estados da Federação em matéria de segurança contra incêndio e pânico.

No mesmo sentido, o Estado de São Paulo pronunciou-se:

"Há normas brasileiras (NBR) que possuem correlação com a segurança contra incêndio em diversos Comitês Brasileiros da Associação Brasileira de Normas Técnicas (ABNT), motivo pelo qual elas foram consultadas na elaboração e revisão de Instruções Técnicas. Importante citar que, da mesma forma que as NBRs são consultadas, outras normas internacionais também são, como por exemplo NFPA, Eurocode, IBC, ISO, $D I N$, dentre outras. Todas as normas e códigos citados, aliado à experiência prática do atendimento a emergências e do serviço de segurança contra incêndio são consideradas para a elaboração das Instruções Técnicas do Corpo de Bombeiros da Polícia Militar do Estado de São Paulo" (CBM da PMESP, 2021).

Quanto à unificação da legislação de segurança contra incêndio e pânico, as Corporações, a pedido dos autores, fizeram comentários acerca da viabilidade e da possibilidade técnica de unificação, registrando os prós e os contras.

Pelos baianos, foi comentado que: 
Revista Científica do Corpo de Bombeiros Militar de Pernambuco

Artigo Publicado no Vol.07 N.19 - Julho a Dezembro 2021 - ISSN 2359-4829

Versão on-line disponível em: http://www.revistaflammae.com

"Será um avanço muito grande, no que diz respeito à segurança contra incêndio e pânico. VANTAGENS: Os projetos e vistorias seguiriam a um único parâmetro de referência para todo o Brasil; os profissionais técnicos poderiam atuar com mais facilidade em todos os Estados da Federação; os Corpos de Bombeiros Militares, de todo o Brasil, teriam uma linguagem única. DESVANTAGENS: Realidades diferentes de cada Estado. Devido às características regionais, seria necessária a adequação ou a criação de algumas normas específicas" (CBMBA, 2021).

Em igual sentido, os mineiros registraram que:

"A criação de uma legislação nacional unificada de segurança contra incêndio e pânico poderia trazer uma série de benefícios, a saber:

- A falta de padronização e de explicação técnica para a existência de tantas divergências entre as diferentes normas de SCIP adotadas em cada um dos Estados da Federação denotam uma ausência de conhecimento técnico, o que pode contribuir para que a sociedade veja as normas com desconfiança e descrédito.

- A ausência de uma abordagem padronizada pode gerar dúvidas quanto aos desígnios da matéria, desestimulando o ensino que, consequentemente, também desmotiva 0 investimento em uma estrutura mais robusta para uma produção contínua do conhecimento, aprimoramento e desenvolvimento de tecnologias, prejudicando sobremaneira a evolução normativa.

- A unificação da legislação simplifica a inserção de disciplinas voltadas à SCIP nos cursos de engenharia e outras especializações, facilitando o ensino de projetistas nesta matéria no Brasil.

- Para uma construtora que possui obras em todo o território nacional, a não unificação da norma impõe maiores custos e dificulta a implantação adequada dos sistemas de SCIP em suas edificações.

- A atuação integrada dos diferentes Corpos de Bombeiros do país na elaboração de normas permitiria reunir os mais bem capacitados militares na área de SCIP, formando um renomado grupo interdisciplinar em âmbito nacional.

De notar que as corporações militares consultadas sinalizaram positivamente ao alinhamento da legislação de segurança contra incêndio e pânico, embora tenham registrado pontos de atenção e possíveis fatores críticos, os quais serão tratados na seção seguinte deste esboço. 


\section{a. ALTERNATIVAS AOS FATORES CRÍTICOS}

Com base nos estudos, foram identificados os seguintes fatores críticos: políticos, legislativos e técnicos. Na primeira seção deste capítulo, esses fatores foram devidamente apresentados. No momento, a proposta é abrir discussão acerca de alternativas de enfrentamento e consequente encaminhamento de propostas tendentes à unificação legislativa.

É certo, por evidentes razões, que produzir e construir tendo por fundamento uma única norma facilitará a atuação nacional de engenheiros e de arquitetos. Em igual medida, são, também, óbvios os óbices ao alinhamento dos inúmeros códigos estaduais de incêndio e pânico. Fatores políticos, legislativos e técnicos informam entraves importantes à codificação nacional.

Politicamente, é possível iniciar discussão no sentido da codificação, seja pela Secretaria Nacional de Proteção e Defesa Civil (SEDEC), seja pela Secretaria Nacional de Segurança Pública (SENASP). São órgãos de projeção nacional que congregam representantes de vários Estados da Federação, notadamente dos diversos corpos de bombeiros militares, o que favorece o debate do tema e a consequente propositura de normas gerais.

É escopo da Defesa Civil antecipar-se às ocorrências danosas, sendo, portanto, ator principal na elaboração de normas técnicas nacionais tendentes à prevenção e à mitigação. A Segurança Pública, notadamente por meio da SENASP, também, possui nítido papel preventivo, a teor das normas constitucionais e dos vigentes Plano e Política Nacional de Segurança Pública e Defesa Social (PNSPDS).

Embora sejam os corpos de bombeiros militares vocacionados à Defesa Civil, o legislador constituinte originário de 1988 manteve os soldados do fogo no orgânico da Segurança Pública. Desta forma, abre-se duas frentes de discussão e trabalho. Defesa Civil e Segurança Pública, enquanto ramos da Defesa Social, devem congregar esforços para prevenir e minimizar as ocorrências e os efeitos danosos dos incêndios com medidas normativas de abrangência nacional. 
No campo legislativo, os inúmeros bombeiros militares com atuação em assessoria parlamentar, especialmente no acompanhamento dos respectivos deputados federais e senadores, são importantes vetores na condução da temática e na propositura de anteprojetos de lei. O anteprojeto é uma espécie de estudo preliminar ou esboço realizado para a elaboração de um projeto. Antes de se dar forma a um projeto de lei, convém ao assessor parlamentar estudar tecnicamente as normas a serem formuladas pelo legislador, de maneira a efetivamente atender ao objetivo colimado.

Nesse sentido, a Federação Nacional dos Bombeiros e da Defesa da Cidadania (FENABOM) promove anualmente encontros e seminários nacionais para discussão de temas técnicos possuindo enorme visibilidade e potencial de abertura de discussão no campo da codificação nacional das normas de segurança contra incêndio e pânico. O Conselho Nacional de Comandantes Gerais das Polícias Militares e Corpos de Bombeiros Militares (CNCG $\mathrm{PM} / \mathrm{CBM}$ ), em igual aspecto, pode emprestar seu capital político para encaminhar propostas de estudos tendentes à unificação.

No aspecto técnico, as divergências regionais e locais encontram pacificação na constante produção normativa dos respectivos corpos de bombeiros militares de situação da edificação ou área de risco mediante resoluções, portarias e instruções técnicas, sem prejuízo ao princípio da legalidade, como, linhas acima, fora esposado respectivo entendimento do STF.

Nesse sentido, os fatores críticos em apreço não parecem significar entraves à codificação, sendo, no entanto, importantes pontos de atenção e discussão, exigindo das corporações estaduais esforço singular na construção teórica de argumentos multidisciplinares que alicercem propostas legislativas tendentes à codificação nacional.

Por fim, apresentam-se as considerações finais, reunindo argumentos acerca da competência para legislar em matéria de segurança contra incêndio e pânico e da viabilidade do alinhamento da legislação correlata e da criação de código nacional de incêndio e pânico. 


\section{CONSIDERAÇÕES FINAIS}

A prevenção de incêndio e pânico, ou de qualquer outro desastre humano, natural ou misto, reveste-se de importância fundamental devido à possibilidade de se evitar perdas humanas e/ou patrimoniais. Para os corpos de bombeiros militares, dentre outras ações de natureza educativa, prevenção deve ser sinônimo de análise de projetos e de vistorias técnicas. Os setores de atividades técnicas e pesquisas são o portão de entrada das demandas voltadas à segurança contra incêndio e pânico. É, portanto, atribuição de importância capital, senão a mais relevante para os soldados do fogo.

Os corpos de bombeiros militares de vários Estados da Federação, já há tempo considerável, possuem papel normatizador e executivo de segurança contra incêndio e pânico. Na Bahia, o Corpo de Bombeiros Militar recebeu tardiamente autorização legal para instituir instruções técnicas normativas, analisar projetos construtivos, vistoriar edificações e áreas de risco e aplicar penalidades administrativas.

Com o advento do novel Código de Incêndio e Pânico baiano, o estabelecimento de uma rotina administrativa de atendimento do público externo e de sistematização das atividades de análise de projetos e de vistorias técnicas passou à ordem do dia. Tarefa que se viu facilitada pelo trabalho, consagrado na prática reiterada das Instituições coirmãs, cuja decana legislação de segurança contra incêndio e pânico dos respectivos Estados informa procedimentos testados, aprovados e retroalimentados pelos públicos interno e externo.

Somente a previsão de texto legal ideal não é suficiente ao desenvolvimento de segurança, notadamente quando sua aplicação implica vultosas somas de recursos pecuniários. A consciência de preservação da vida é aspecto intrínseco aos valores culturais e sociais vigentes. Assim, inserir normatização aos diversos setores econômicos da sociedade brasileira, com, 
não raro, consequente aumento dos custos de produção e de construção, é tarefa de singular complexidade, carecendo de ampla discussão e de debate na esfera política e nos meios de comunicação. Daí, a defesa ampla e irrestrita dos autores pelo alinhamento das normas de segurança contra incêndio e pânico em todo território nacional, o que coaduna com os anseios profissionais de engenheiros e arquitetos entrevistados.

O sentido de uma codificação nacional visa, não apenas, a estabelecer norma uniforme aos diversos Estados da Federação, mas, principalmente, a abrir o debate da segurança contra incêndio e pânico em todo o país, fomentando cultura de prevenção às regiões com menor atenção aos aspectos preventivos e protetivos ${ }^{9}$. À vista disto, mesmo em um país de dimensões continentais, visualiza-se possibilidade de alinhamento das normas de procedimento administrativo, de exigências mínimas de segurança, de fiscalização e de aplicação de sanções administrativas. Esforço que visa a evitar multiplicidade de tratamento legal por mero critério geográfico e que possui enorme potencial de difusão e de cumprimento espontâneo das normas de segurança, situação duramente censurada pelos entrevistados.

Os inúmeros entraves ao alinhamento, aqui apontados como fatores críticos, quer políticos, quer legislativos, quer técnicos, não podem significar impedimento à defesa do patrimônio histórico, artístico e cultural e, muito menos, à proteção de vidas humanas. A defesa da integridade física das pessoas é argumento suficiente à implementação dos custos de produção e de construção, até porque o desastre impõe, não raro, paralisação da vida social com catastróficos prejuízos econômicos e financeiros.

Nesse sentido, o desalinhamento legislativo, mesmo não significando, por si só, incremento do risco, a multiplicidade de normas, muitas das quais divergentes, impõe tendência degenerativa à formação de cultura de segurança nos setores sociais e produtivos. Assim, um código nacional de segurança contra incêndio e pânico terá o condão de inaugurar discussão ampla e

\footnotetext{
${ }^{9}$ Vide Nota de Rodapé 15.
} 
uniforme sobre o tema, além de divulgação da necessidade de conhecimento e cumprimento das normas técnicas. Tais tendências possuem potencial de contribuir para construção doutrinária de disciplinas acadêmicas dos cursos de níveis médio e superior, atendendo reclame do legislador federal. Os pontos, neste parágrafo alinhavados, refletem resumo dos resultados alcançados em pesquisa de abrangência nacional.

Farta legislação federal dá conta de precedente legislativo, não apenas demonstrando tendência ao alinhamento, mas, principalmente, impondo, ao nível nacional, normas jurídicas de prevenção e de proteção da vida humana, inclusive, com mandamentos expressos à segurança contra incêndio e pânico e aos corpos de bombeiros militares do país.

Por tudo exposto, tal situação suscita tendência legislativa unificadora e o alinhamento tácito à legislação paulista neutraliza qualquer dúvida acerca da possibilidade e contribuição de codificação nacional da legislação de segurança contra incêndio e pânico. Não se trata de atribuir à legislação bandeirante a qualidade de régua para construção de um código nacional. Sua citação teve por base regra ordinária de experiência que aponta para legislação paulista como base da maioria das legislações de outros estados, conforme apontou pesquisa dos autores. Por evidente, a construção de um código nacional requer ampla participação e discussão dos estados federados, sem qualquer precedência geográfica ou política de um sobre o outro.

\section{REFERÊNCIAS}

BAHIA. Lei ํㅜ 12.209, de 20 de abril de 2011. Dispõe sobre o processo administrativo, no âmbito da Administração direta e das entidades da Administração indireta, regidas pelo regime de direito público, do Estado da Bahia. 2011. Disponível em: http://www.legislabahia.ba.gov.br/documentos/lei-no-12209-de-20-de-abril-de2011. Acesso em: 2 set. 2020. 
Revista Científica do Corpo de Bombeiros Militar de Pernambuco

Artigo Publicado no Vol.07 N.19 - Julho a Dezembro 2021 - ISSN 2359-4829

Versão on-line disponível em: http://www.revistaflammae.com

BAHIA. Lei no 12.929, de 27 de dezembro de 2013. Dispõe sobre a

Segurança Contra Incêndio e Pânico nas edificações e áreas de risco no Estado da Bahia. Disponível em:

http://www.legislabahia.ba.gov.br/documentos/lei-no-12929-de-27-de-

dezembro-de-2013. Acesso em: 2 set. 2020.

BAHIA. Polícia Militar da Bahia. Portaria no 02/05/2005, publicada no BIO no 15, de 2 a 6 de maio de 2005, Coordenadoria de Operações de Bombeiros Militares. Salvador, 2005.

BAHIA. Polícia Militar da Bahia. Portaria no 10 - CG/14, publicada no BGO no 27, de 7 de fevereiro de 2014, Comando Geral da PMBA. Salvador, 2014.

BERTO, Antônio Fernando. Aspectos Técnicos do Projeto Arquitetônico Visando a Segurança Contra Incêndio: gestão de segurança contra incêndio desde o projeto arquitetônico. Apostila (Curso de Especialização em Segurança Contra Incêndio e Pânico). Universidade Salvador, 2015. 3-4p.

BRASIL. Constituição da República Federativa do Brasil de 1988.

Disponível em:

http://www.planalto.gov.br/ccivil_03/constituicao/constituicaocompilado.htm. Acesso em: 2 set. 2020.

BRASIL. Lei no 8.078 , de 11 de setembro de 1990. Dispõe sobre a proteção do consumidor e dá outras providências. Disponível em:

http://www.planalto.gov.br/ccivil_03/leis//8078.htm. Acesso em 2 set. 2020.

BRASIL. Lei no 9.784, de 29 de janeiro de 1999. Regula o processo administrativo no âmbito da Administração Pública Federal. Disponível em: http://www.planalto.gov.br/ccivil_03/leis//9784.htm. Acesso em: 2 set. 2020.

BRASIL. Lei $n^{0} 12.608$, de 10 de abril de 2012. Institui a Política Nacional de Proteção e Defesa Civil - PNPDEC; dispõe sobre o Sistema Nacional de Proteção e Defesa Civil - SINPDEC e o Conselho Nacional de Proteção e Defesa Civil - CONPDEC; autoriza a criação de sistema de informações e monitoramento de desastres; altera as Leis ํㅗ 12.340 , de $1^{\circ}$ de dezembro de $2010,10.257$, de 10 de julho de 2001, 6.766, de 19 de dezembro de 1979, 8.239, de 4 de outubro de 1991, e 9.394, de 20 de dezembro de 1996; e dá outras providências. Disponível em:

http://www.planalto.gov.br/ccivil_03/_ato2011-2014/2012/lei//12608.htm.

Acesso em: 29 dez. 2020.

BRASIL. Lei federal $n^{\circ} 13.425$, de 30 de março de 2017. Estabelece diretrizes gerais sobre medidas de prevenção e combate a incêndio e a desastres em estabelecimentos, edificações e áreas de reunião de público; altera as 
Revista Científica do Corpo de Bombeiros Militar de Pernambuco

Artigo Publicado no Vol.07 N.19 - Julho a Dezembro 2021 - ISSN 2359-4829

Versão on-line disponível em: http://www.revistaflammae.com

Leis $n^{\circ} \mathrm{s} 8.078$, de 11 de setembro de 1990, e 10.406, de 10 de janeiro de 2002 - Código Civil; e dá outras providências. Disponível em: http://www.planalto.gov.br/ccivil_03/_ato2015-

2018/2017/lei/13425.htm\#: :text=Estabelece\%20diretrizes\%20gerais\%20sobre \%20medidas,Civil\%3B\%20e\%20d\%C3\%A1\%20outras\%20provid\%C3\%AAncia s. Acesso em: 27 dez. 2020.

BRASIL. Lei $n^{0} 13.675$, de 11 de junho de 2018a. Disciplina a organização e o funcionamento dos órgãos responsáveis pela segurança pública, nos termos do $\$ 7^{\circ}$ do art. 144 da Constituição Federal; cria a Política Nacional de Segurança Pública e Defesa Social (PNSPDS); institui o Sistema único de Segurança Pública (SUSP); altera a Lei Complementar oํ 79, de 7 de janeiro de 1994, a Lei o 10.201, de 14 de fevereiro de 2001, e a Lei no 11.530, de 24 de outubro de 2007; e revoga dispositivos da Lei no 12.681, de 4 de julho de 2012. Disponível em: http://www.planalto.gov.br/ccivil_03/_ato2015-

2018/2018/lei/L13675.htm. Acesso em: 27 dez. 2020.

BRASIL. Ministério da Segurança Pública. Secretaria Nacional de Segurança Pública. Portaria no 151, de 26 de setembro de 2018b. Aprova o Regimento Interno da Secretaria Nacional de Segurança Pública. 2018b. Disponível em: https://www.in.gov.br/materia/-

/asset_publisher/Kujrw0TZC2Mb/content/id/45572992/do1-2018-10-17-portarian-151-de-26-de-setembro-de-2018-45572843. Acesso em: 29 dez. 2020.

BRASIL. Lei federal $n^{0} 13.722$, de 4 de outubro de 2018c. Torna obrigatória a capacitação em noções básicas de primeiros socorros de professores e funcionários de estabelecimentos de ensino públicos e privados de educação básica e de estabelecimentos de recreação infantil. Disponível em: http://www.planalto.gov.br/ccivil_03/_ato2015-

2018/2018/lei/L13722.htm\#: :text=L13722\&text=LEl\%20N\%C2\%BA\%2013.722 \%2C\%20DE\%204,de\%20estabelecimentos\%20de\%20recrea\%C3\%A7\%C3\%A 3o\%20infantil. Acesso em: 27 dez. 2020.

BRASIL. Ministério da Segurança Pública. Secretaria Nacional de Segurança Pública. Plano e Política Nacional de Segurança Pública e Defesa Social. Sistema único de Segurança Pública. 2018d. 2018 - 2028. 66-67p.

BRASIL. Ministério da Justiça e Segurança Pública. Secretaria Nacional de Segurança Pública. Portaria $n^{\circ} 108$, de 12 de julho de 2019. Institui Modelo Nacional de Regulamento de Segurança contra Incêndio e Emergências. Brasília, 2019.

BRASIL. Ministério do Desenvolvimento Regional. Sistema Nacional de Proteção e Defesa Civil. Composição. Secretarias Nacionais. Proteção e Defesa Civil. 2020. Disponível em: https://www.gov.br/mdr/pt- 
Revista Científica do Corpo de Bombeiros Militar de Pernambuco

Artigo Publicado no Vol.07 N.19 - Julho a Dezembro 2021 - ISSN 2359-4829

Versão on-line disponível em: http://www.revistaflammae.com

br/composicao/secretarias-nacionais/protecao-e-defesa-civil. Acesso em: 2 set. 2020.

BRASIL. Ministério do Trabalho e Emprego. Secretaria de Inspeção do Trabalho. Portaria SIT no 221, de 06 de maio de 2011. Diário Oficial da União. Brasília, DF, 10maio. 2011. Disponível em:

https://enit.trabalho.gov.br/portal/images/Arquivos_SST/SST_NR/NR-23.pdf. Acesso em: 2 set. 2020.

SÃO PAULO. Decreto oㅜ 63.911, de 10 de dezembro de 2018. Institui o Regulamento de Segurança contra Incêndio das edificações e áreas de risco no Estado de São Paulo e dá outras providências. Disponível em: http://www.ccb.policiamilitar.sp.gov.br/dsci_publicacoes2/_lib/file/doc/decreto_6 3.911.pdf. Acesso em: 2 set. 2020.

SILVA, Cláudio Barros. Ação Direta de Inconstitucionalidade. Lei Municipal no 2.446/2001 do Município de Santo Ângelo. Possibilidade de o Município legislar sobre matéria referente à prevenção e proteção contra incêndios, nos termos do artigo 30, inciso II, da Constituição Estadual. Presença de interesse local. Contudo, inconstitucionalidade material frente ao princípio constitucional da isonomia. Ação procedente. Parecer do Procurador-Geral de Justiça do Rio Grande do Sul na Ação Direta de Inconstitucionalidade ㄲo 70003272309 (TJRS), 11 de janeiro de 2002. Disponível em: http://www.mprs.mp.br/adins/arquivo/anexo/504687/?filename=000062002 001 .DOC. Acesso em: 2 set. 2020. 